\title{
Finding Minimal Perfect Hash Functions
}

\author{
Kevin Karplus* \\ Gary Haggard
}

September 1984 TR 84-637

Computer Science Department

Cornell University

Ithaca, NY 14853

- Computer Science Department and School of Electrical Engineering.

Cornell University

s Computer Science Department

University of Maine at Orono

(work done while visiting Cornell) 


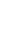




\begin{abstract}
A heurisitic is given for finding minimal perfect hash functions without extensive searching. The procedure is to construct a set of graph (or hypergraph) models for the dictionary, then choose one of the models for use in constructing the minimal perfect hashing function. The construction of this function relies on a backtracking algorithm for numbering the vertices of the graph. Careful selection of the graph model limits the time spent searching. Good results have been obtained for dictionaries of up to 181 words. Using the same techniques, non-minimal perfect hash functions have been found for sets of up to 667 words.
\end{abstract}

\title{
Introduction
}

A hash function is a mapping from a set of keys $\boldsymbol{K}$ to $n$ consecutive integers (usually $[0, n-1]$ or $[1, n])$ ). If the mapping is one-to-one, the function is a perfect hash function. If the mapping is one-to-one and onto $(|\boldsymbol{K}|=n)$, the mapping is a minimal perfect hash function. In this paper, we only examine cases where the keys are words (that is, short sequences of alphabetic characters), but the techniques can be applied to other kinds of keys as well.

Hash functions are used for fast searching of sets of keys. Hashing algorithms provide constant time searches on the average, but $O(|F|)$ worst-case behavior. Using a perfect hash function allows constant-time performance in the worst case. However, perfect hash functions can only be found when the set of keys is fixed.

Minimal perfect hash functions offer a slight storage savings over arbitrary perfect hash functions, and make the search more interesting. The techniques given in this paper can be used to generate both minimal and non-minimal perfect hash functions. 


\section{Previous results}

Ordinary hash functions are cheap to compute, and families of good hash functions have been described in the literature [CW]. A tempting technique is to try arbitrary hash functions until a perfect one has been found. This approach was investigated in [S] for non-minimal perfect hash functions, but only small sets were considered. If we map $m$ keys to $n$ integers, there are $n$ hash functions, of which only $n !(n-m)$ ! are perfect. The table below gives the density of perfect hash functions for small values of $m$ and $n$. Even for fairly small sets of words, prefect hash functions are rare, and minimal perfect hash functions are very rare indeed. Finding perfect hash functions by generating random good hash functions is only feasible for very small sets, or for moderately small sets and much larger hash ranges.

$\begin{array}{rrrrrrrrrrr}n- & -10 & & 20 & & 30 & & 40 & & 50 & \\ 20 & 65.5 & 10^{-3} & 23.2 & 10^{-9} & 0 & & 0 & & 0 & \\ 40 & 293 . & 10^{-3} & 3.05 & 10^{-3} & 195 . & 10^{-9} & 67.5 & 10^{-18} & 0 & \\ 60 & 452 . & 10^{-3} & 27.9 & 10^{-3} & 142 . & 10^{-6} & 25.6 & 10^{-9} & 28.4 & 10^{-15} \\ 80 & 556 . & 10^{-3} & 74.6 & 10^{-3} & 1.90 & 10^{-3} & 6.60 & 10^{-6} & 1.89 & 10^{-9} \\ 100 & 628 . & 10^{-3} & 130 . & 10^{-3} & 7.79 & 10^{-3} & 112 . & 10^{-6} & 307 . & 10^{-9} \\ 120 & 680 . & 10^{-3} & 187 . & 10^{-3} & 18.97 & 10^{-3} & 636 . & 10^{-6} & 6.14 & 10^{-6}\end{array}$

In [C] a method for finding minimal perfect hash functions was presented. Only functions of the following form were considered:

$h($ key $)=g$ (first letter $)+g($ last letter $)+$ length (key). where $\mathrm{g}$ (letter) is computed by table lookup. The technique consisted of ordering the words of the dictionary, then doing a backtracking search to assign appropriate values to the letters. The method works well for small dictionaries, but fails for larger ones.

In this paper, we will investigate a family of functions which includes the form used in [C] as a special case. Minimal perfect hash functions can be found in reasonable amounts of time for much larger sets of words than previously reported.

\section{Word graphs (and hypergraphs)}

The first and last letters of a word are not always a good choice for hashing functions. In [C], the set of PASCAL pre-defined identifiers was used as an example only after eliminating ODD, since the pair ODD and ORD could not be distinguished. For three letter month abbreviations, the second and third 
letter were used, to distinguish JAN and JUN. With a general set of words, it is not clear a priori how to pick a pair of letter positions to use for generating a perfect hash function. We consider several candidate letter positions, and choose the smallest $k$-tuple of positions likely to yield a perfect hash function. Upper and lower case letters are considered equivalent, and all other characters (such as apostrophes and hyphens) are removed from the word before hashing. The hash functions themselves are of the form:

$h($ word $)=8_{1}$ (letter) $+\ldots+8_{k}($ letter $)+$ length(word $)$

where each function $8_{i}$ is a table lookup for a different letter position. The class of hash functions is reduced to the hash functions generated in [C] if $k$ is two, if the positions chosen are the first and last letters, and if the two functions $8_{1}$ and $8_{2}$ are identical.

In the program implementing the search for perfect hash functions, positions of letters in a word of length $L$ are numbered from 0 to $L-1$. The candidate positions tried by the program are generated by the following functions: 0 , $L-1,(L-1) \bmod 2,(L-1) \bmod 3,(L-1) \bmod 1,(L-1) \bmod 5,1,2,3$, 1, $5, L-2, L-3, L-1, L-5,2 \bmod L, 3 \bmod L, 1 \bmod L, 5 \bmod L, 6$ $\bmod L, 7 \bmod L, 8 \bmod L, L / 2, L / 3,2 L / 3, L / 1$, and $3 L / 1$, where $P$ $\bmod y$ means the remainder when $\mathrm{x}$ is divided by $\mathrm{y}$, and all the divisions truncate non-integers. If the computed position is less than zero, then zero is used, and if it is $L$ or larger, $L-I$ is used.

When the dictionary has only a few different lengths of words, then several of the functions for generating candidate positions generate the same positions. In such a case, only the first of the equivalent functions is used.

Definition: Let $\boldsymbol{X}$ be a set of words, $w$ be a member of $\boldsymbol{X}$, and $w_{p}$ be the letter at position $p$. The word (hyper-)graph $G\left(p_{f}, \ldots p_{f}\right)$ over $\boldsymbol{K}$ is the k-partite hypergraph formed as follows:

The vertex set $\mathrm{V}$ is the disjoint union of $\mathrm{V}_{\mathrm{pi}}$, where $\mathrm{V}_{\mathrm{p}}=$ (letters in words of $\boldsymbol{F}$ occurring at position $p$ ).

Each (hyper-)edge is labeled with a word of $K$, has $k$ vertices, and has $w_{p_{i}}$ as its vertex in $v_{p_{i}}$.

The dimension of the word hypergraph is the number of vertices in each hyperedge. A hypergraph of dimension two is an ordinary graph, and hypergraphs of degree zero and one are possible. 
A hash function can be defined by labeling each verter with a number, the hash value for a word being the sum of the labels on the vertices of the hyperedge plus the length of the word. The functions $\mathrm{g}_{\mathrm{i}}$ (letter) are undefined for letters not in the graph. Arbitrarily assigning them a large value makes it probable that words not in the dictionary have hash values outside the image of $\boldsymbol{K}$.

As an example of a word graph, consider $K=(\mathrm{JAN}, \mathrm{FEB}, \mathrm{MAR}, \mathrm{APR}, \mathrm{MAY}, \mathrm{JUN}$, JUL, AUG, SEP, OCT, NOV, DEC). Here is the graph $G(1,2)$ (position numbering starts with 0 , so $G(1,2)$ uses the second and third letters) :
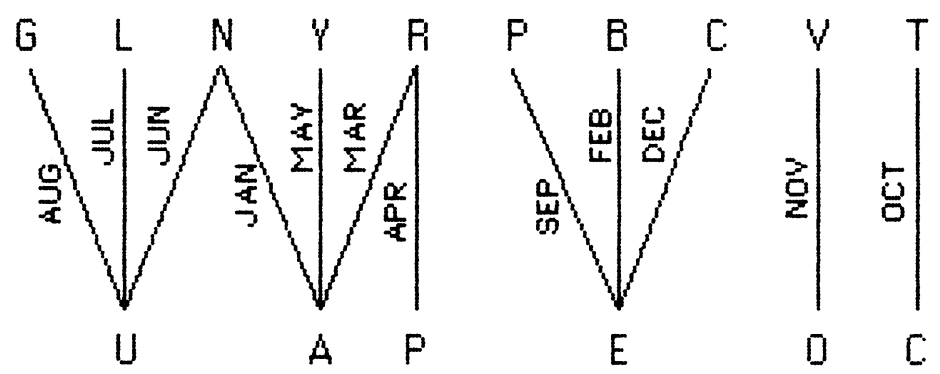

A word graph can have several edges with the same pairs of vertices. For example, in $G(0,2)$ for the month names there are two edges $\mathrm{J}-\mathrm{N}$, corresponding to the words JAN and JUN. A perfect hash function is only possible in this scheme if all edges with the same vertices correspond to words of different lengths.

The steps in finding a minimal perfect hash function are: 1) generate a collection of word graphs (or hypergraphs), 2) choose one which looks promising, and 3) assign values to the vertices of the graph in such a ways as to assign distinct values to each edge.

Edges incident on vertices of degree one can be assigned any desired hash value, since the verter can be assigned a value independent of any other vertex value. Thus the vertex assignment problem can be simplified somewhat by deleting all edges containing a verter unique to that edge. The reduced graph may have new vertices of degree one, allowing more edges to be deleted. Repeating this process eventually results in a graph with no vertices of degree one. The edges removed are referred to as tree edges, and are assigned hash values in reverse order of their removal, after all the edges in the reduced graph have been assigned values.

In $G(1,2)$ for month name abbreviations, all the edges are tree edges, so a perfect hash function can be found immediately. The tree edges could be 
removed in the order: OCT, NOV, DEC, SEP, FEB, AUG, JUL, MAY, APR, MAR, JUN, JAN. Arbitrarily choosing $J A N=1, F E B=2, \ldots, D E C=12$, we can assign verter values as follows:

\begin{tabular}{|c|c|c|}
\hline$v_{1}$ & $v_{2}$ & \\
\hline$A=-2$ & $N=0$ & $J A N=1$ \\
\hline \multirow[t]{2}{*}{$U=3$} & & $J U N=6$ \\
\hline & $R=2$ & $M A R=3$ \\
\hline \multirow[t]{4}{*}{$P=-1$} & & $\mathrm{APR}=4$ \\
\hline & $Y=4$ & $M A Y=5$ \\
\hline & $L=1$ & $\mathrm{JUL}=7$ \\
\hline & $G=2$ & $A \cup G=8$ \\
\hline \multirow[t]{3}{*}{$E=-1$} & $B=0$ & $\mathrm{FEB}=2$ \\
\hline & $P=7$ & SEP $=9$ \\
\hline & $C=10$ & $D E C=12$ \\
\hline $0=8$ & $V=0$ & $\mathrm{NOV}=11$ \\
\hline$C=7$ & $T=0$ & $O C T=10$ \\
\hline
\end{tabular}




\section{Choosing a word graph}

The most important criterion for choosing a word graph is that it must allow a perfect hash function. A necessary, but not sufficient, condition is that all edges with the same vertices correspond to words of different lengths. Since tree edges make finding a minimal perfect hash function much easier, an obvious second criterion for a good word graph is that it maximize the number of tree edges.

Vertex value assignments are easier if the effects of an assignment are fairly local in the graph. The program does not check connectivity of the graph, but tries to maximize the number of vertices remaining after tree edges have been removed. By maximizing the number of tree edges and the number of vertices remaining, the total number of vertices is kept high and the average degree low.

There is only one possible graph with dimension zero. It can form a perfect hash function only if all the word lengths are different, and a minimal perfect hash function only if the lengths are consecutive. It is very rare that a minimal perfect hash function can be found so easily.

Each candidate position function generates a graph of dimension one. The program generates all these graphs, counting their vertices and tree-edges. In the examples tried, only the 22 word random set (r022) had a graph of dimension one in which all words mapped to distinct edges.

The program could continue generating all graphs of dimension 2, 3, and so on until a graph in which all words are distinct edges is found. Unfortunately, the process of building a graph and counting the tree-edges is fairly expensive. A heuristic was introduced to generate only graphs that are likely to have all edges distinct and to have many tree-edges. The best few (four in the program) position tuples of dimension $k-1$ are kept, and all possible extensions of them to $k$ tuples are tried. The "best" tuple is defined as the weighted sum of the total number of edges, the number of tree-edges, and the number of vertices.

Nine experiments were run to try tuning the weights. The program tried to find hash functions for seventeen sets of words (through $\mathrm{r} 181$ in the table below). In every case a graph which distinguished the words was found, but the search for a hash function was interrupted if it took too long. Some larger sets were also tried, and graphs were found, but no minimal perfect 
hash functions. A weighting was considered better for a particular dictionary if it generated a different graph and took less total time in the search for a hash function. For successful searches, most of the time was spent building graphs and counting tree-edges. For unsuccessful searches, most of the time was spent trying to find a vertex value assignment.

\begin{tabular}{|c|c|c|c|}
\hline $\begin{array}{l}\text { Edge } \\
\text { weight }\end{array}$ & $\begin{array}{l}\text { Tree-edge } \\
\text { weight }\end{array}$ & $\begin{array}{l}\text { Vertex } \\
\text { weight }\end{array}$ & comparison with default \\
\hline 2 & 6 & 1 & (this is the default) \\
\hline 1 & 3 & 1 & (ibm \& r 139 worse) \\
\hline 1 & 3 & -1 & (r066, r 124, \& r 162 worse) \\
\hline 0 & 1 & 0 & (r115, r162 better. r124, r181 worse) \\
\hline 0 & 0 & 1 & (most sets worse) \\
\hline 1 & 0 & 0 & (most sets worse) \\
\hline 1 & 3 & 0 & (r066 better, $\mathrm{r} 162$ worse) \\
\hline 2 & 8 & 1 & $=$ \\
\hline 2 & 4 & 1 & (r 124 better. ibm, pasc-all worse) \\
\hline
\end{tabular}

From these experiments, it seems that the number of tree-edges is the best predictor of which tuples to expand, and that the total number of edges is more important than the number of vertices. Below is a more detailed table of the graphs chosen for the default weighting, including some larger sets that were not used in the tuning. The table gives: the name of the set, the number of words in the set, the number of tree edges found in the hypergraph chosen, the number of vertices left after removing the tree edges, the excess space allowed for the hash function (and the amount actually used) expressed as a fraction of the number of words, and the position functions used to generate the hypergraph.

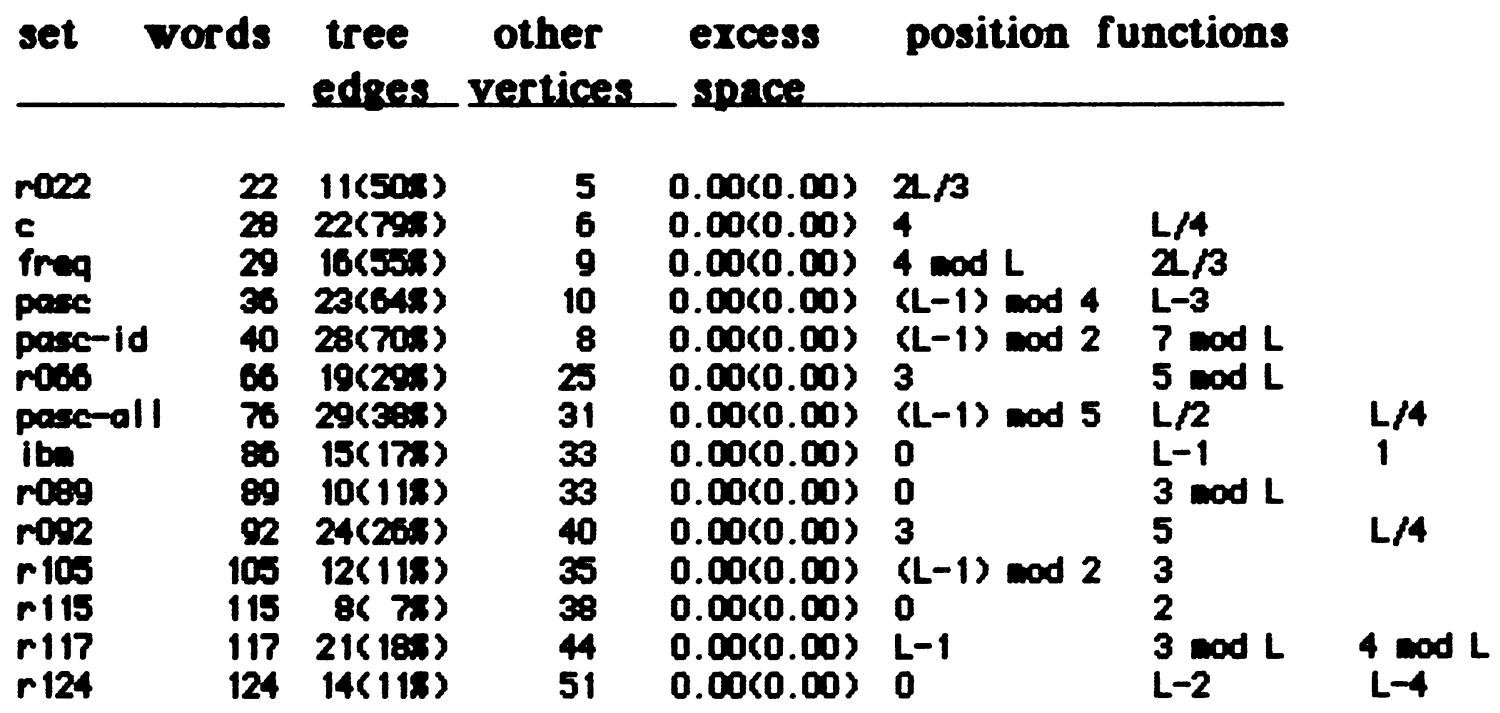




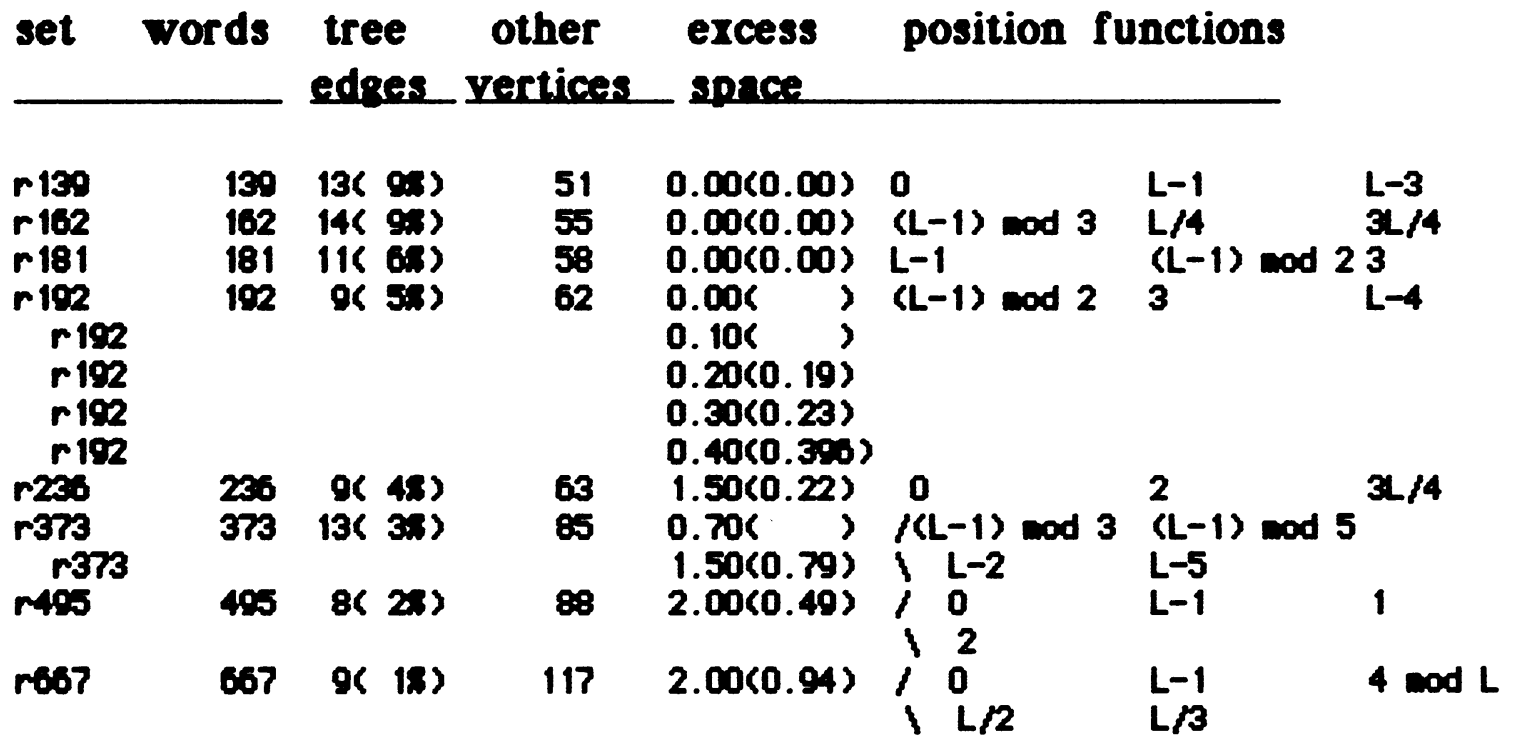

One larger set ( $\mathrm{r} 992$ ) was tried, but no hypergraphs of dimension 5 or less were found with distinct edges for all the words of the set. Because of some poor early decisions in implementation, the program would require major restructuring to handle hypergraphs of dimension six or more.

For small sets, two position functions usually suffice to form graphs with no duplicate edges. However, note that the set pasc-all, with only 76 words, needs three position functions to avoid duplication. In fact, the seven words (CASE, ELSE, PAGE, READ, REAL, TRUE, TYPE) contained in pasc-all require three position functions by themselves. (Consider all possible pairs of positions for four-letter words: 0\&1, 0\&2, 1\&2 READ=REAL; 0\&3 TRUE=TYPE; $1 \& 3$ CASE=PAGE; $2 \& 3$ CASE=ELSE.) Some of the larger sets (for which no minimal perfect hash function has yet been found) apparently require four, five, or more position functions to avoid duplicate edges.

\section{Assigning vertex values}

After the position functions have been chosen and the word hypergraph built, values have to be assigned to all vertices. The tree-edges can be removed and the associated vertices assigned values in reverse order after the rest of the vertices have values. For the main body of the graph, the vertex assignment proceeds as follows:

1) choose a vertex

2) if there is no legal assignment,

backtrack and change a previous choice

3) otherwise, assign the smallest legal value to the vertex

(or 0 , if the vertex value is unconstrained)

4) 80 back to 1 until all vertices assigned. 
The word hypergraph is stored redundantly, so that the edges incident on a particular vertex or the vertices in a particular edge can be quickly found. A number of auxiliary data structures are used to speed up the vertex-value assignment. For example, keeping the set of unused edge values makes it easier to determine what the legal values for a vertex are. Also, keeping a stack of the value assignments makes backtracking easier.

The simplest scheme would be to have a fixed ordering for the vertices, and to do simple backtracking (undoing the most recent choice) when a conflict is found. This scheme worked well for the small assignments of [C], but can take a very long time on larger, more complicated graphs. Various enhancements were tried to speed up the vertex-assignment search. They can be divided into two classes: vertex-choice heuristics and backtracking shortcuts.

The vertex-choice heuristics attempt to speed things up by choosing the most difficult vertices first. Not only does this reduce backtracking by making conflicts appear sooner, it also reduces the number of conflicts, since the difficult vertices are assigned while there are still many unused edge values. The backtracking shortcuts attempt to speed up the search by eliminating combinations of assignments that can not work. For example, if two edges incident on the current vertex have the same edge value, only changes to one of the other vertices of the edges will break the conflict. A simple backtracking scheme could waste a long time undoing and retrying more recent assignments that can't affect the conflict. 


\section{Vertez-choice heuristics}

The vertex-choice heuristics used are fairly simple. First, find the set of edges with the fewest unassigned vertices (not counting edges with all vertices assigned values). Call this set $\mathrm{E}_{\min }$. Next, choose the best vertex in one of these edges. "Best" can be defined in one of three ways:

Most) choose the vertex with the most edges in $\mathrm{E}_{\min }$.

Widest) choose the vertex with the widest range of partial sums for edges in $E_{\text {min }}$.

Most \& Widest) of the vertices with the most edges in $\mathrm{E}_{\min }$ choose the vertex with the widest range of partial sums.

or the three, "Most \& Widest" works best. This verter ordering scheme works well for hypergraphs of dimension one and two, but not as well for higher dimensions. A more sophisticated verter-choice scheme may be needed to handle dictionaries of more than one or two hundred words efficiently.

\section{Backtracking heuristics}

The backtracking heuristics are more complicated than the verter-choice ones. Successful hash function searches backtrack rarely, and spend more time building graphs and counting tree edges than doing the vertex assignment. Failing hash function searches spend almost all their time attempting vertex-value assignments. More intelligent backtracking heuristics could increase the size of dictionary that the program could handle.

It is difficult to report on the exact state of the backtracking heuristics, since they were written incrementally. After each modification, traces were done to look for patterns in the backtracking, and changes made to reduce the most obvious wasted effort. Changes that made matters worse were either undone or fired with an additional heuristic. Since the heuristics interact, it is difficult to assign credit to any particular heuristic.

Currently, the only edges that affect the vertex value are those which have only the chosen vertex unassigned. We call these the almost completed edges. If there are no such edges, the vertex is assigned an arbitrary value and another vertex is chosen. The program offers the choice of assigning either zero or the smallest available edge weight divided by the number of vertices still unassigned in the edge to each such free vertex. Although 
different hash functions are found in each case, the search time is not affected much by this option.

There are three different conflicts that can cause backtracking:

edge conflict) two different almost completed edges have the same partial sum.

too big) the range of partial sums for almost completed edges is larger than the range of unused edge values.

no fit) every vertex assignment will make the almost completed edges have values that are unused by other edges.

Each type of conflict triggers a different backtracking method.

For edge conflicts, vertex values are unassigned (and popped off the backtrack stack) until the partial sums of the edges in conflict differ. It is not enough to pop vertices until a vertex of one of the edges is removed, as that vertex may be included in both edges, so changing its value would not remove the conflict. The program proceeds forward again, trying to find a larger value for the last vertex popped off the stack.

For "too-big" conflicts, vertices are popped until

1) the last vertex popped is

in the almost completed edge with the smallest partial sum, but not in the one with the highest partial sum,

or 2) a vertex assignment can be made so the partial sums of the almost completed edges will fit.

In the second case, one extra vertex needs to be popped to prevent the search from entering an infinite loop. The loop does occur sometimes if this precaution is not taken. What happens is that two sets of edges are alternately put into the same space, and undoing one set of assignments leaves just enough room to do the other set, but not to do both. The extra vertex popping ensures progress, but is risky, in that a solution to the vertex assignment problem may be skipped. This is not very dangerous, since solutions have to be fairly common for the search technique to have any chance of being efficient.

The vertex that triggered the "too-big" conflict and other popped vertices of the almost completed edge with the highest partial sum are added to a set of vertices to try immediately. When there are vertices in that set, the vertex choice heuristics are disabled and a vertex is taken from the set instead. This shortcut reduces the backtracking enormously, since extraneous assignments are not tried until the known conflict has been resolved. 
For "no-fit" conflicts, vertices are popped until some vertex of an almost completed edge has been popped. A slight change was added to speed the search. The backtracking is not stopped by vertices of the almost completed edge with the highest partial sum. Since reassigning them raises the partial sum of the highest edge, it is unlikely to result in the conflict being resolved. Before this change was made, several "no-fit" conflicts occurred together, followed by a "too-big" conflict when the partial sums got far enough apart. The conflict-triggering vertex and any popped vertices of the highest edge are added to the set of vertices to try next.

Optionally, the backtracking from a "no-fit" conflict can be stopped when an assignment is possible for the vertex triggering the conflict. This option was not turned on for the tests reported here, as preliminary tests showed that it increased rather than reduced the backtracking.

Here is a summary of the types of conflicts for each set (using the position functions of the earlier table):

\begin{tabular}{|c|c|c|c|c|c|c|}
\hline $\begin{array}{l}\text { word } \\
\text { set }\end{array}$ & & $\begin{array}{l}\text { vertices } \\
\text { chnnged }\end{array}$ & $\begin{array}{l}\text { edge } \\
\text { conflicts }\end{array}$ & $\begin{array}{l}\text { too-bis } \\
\text { conflict: }\end{array}$ & $\begin{array}{l}\text { no- } \\
\text { con }\end{array}$ & $\begin{array}{l}\text { Iit } \\
\text { llicts }\end{array}$ \\
\hline r022 & & 0 & 0 & 0 & 0 & \\
\hline c & & 1 & 1 & 0 & 0 & \\
\hline freq & & 2 & 1 & 0 & 0 & \\
\hline pasc & & 0 & 0 & 0 & 0 & \\
\hline pasc- $i$ & & 0 & 0 & 0 & 0 & \\
\hline r066 & & $?$ & 3 & 0 & 0 & \\
\hline pasc-o & & 0 & 0 & 0 & 0 & \\
\hline ibn & & 40 & 0 & 16 & 0 & \\
\hline r089 & & 1 & 1 & 0 & 0 & \\
\hline r092 & & 1 & 1 & 0 & 0 & \\
\hline r105 & & 59 & 3 & 0 & 11 & \\
\hline r115 & & 106 & 3 & 1 & 36 & \\
\hline r11? & & 10 & 1 & 1 & 3 & \\
\hline r124 & & 221 & 10 & 20 & 4 & \\
\hline r139 & & 137 & 20 & 0 & 94 & \\
\hline r162 & & 93 & 1 & 3 & 21 & \\
\hline$r 181$ & & 223 & $\theta$ & 2 & 104 & \\
\hline r192 & .0 & 394 & 12 & 4 & $16 ?$ & KILLED \\
\hline r192 & .1 & 751 & 30 & 6 & 313 & KILLED \\
\hline r192 & .2 & 180 & 5 & 1 & 107 & \\
\hline$r 192$ & .3 & 58 & 4 & 1 & 5 & \\
\hline
\end{tabular}




\begin{tabular}{lrrrrrr}
$\begin{array}{l}\text { Word } \\
\text { set }\end{array}$ & $\begin{array}{c}\text { vertices } \\
\text { changed }\end{array}$ & $\begin{array}{c}\text { edge } \\
\text { conflicts }\end{array}$ & $\begin{array}{c}\text { too-big } \\
\text { conflicts }\end{array}$ & $\begin{array}{c}\text { no-fit } \\
\text { conflicts }\end{array}$ \\
\hline r192 & .4 & 1 & 1 & 0 & 0 & \\
r236 & 1.5 & 44 & 8 & 0 & 0 & \\
r373 & .7 & 292 & 1 & 0 & 291 & KILLED \\
r373 & 1.5 & 92 & 8 & 0 & 0 & \\
r495 & 2.0 & 38 & 13 & 0 & 0 & \\
r667 & 2.0 & 372 & 39 & 0 & 0
\end{tabular}

It is interesting that it is much easier to find perfect hash functions for the sets handled in $[\mathrm{C}]$ with the new method. The month names example is all tree-edges, so can be trivially done by hand. Two sets (pasc and pasc-id) require no backtracking, and freq only backtracks once, so all three could have been done by hand. As a matter of record, both freq and pasc were succesfully done by hand to determine the effectiveness of the tree-edge removal before the search program was written.

\section{Timing analysis}

The vertex-assignment search is potentially an exponential search. It usually finishes quickly for small sets, and may run for long times without finishing on slightly larger ones. The worst-case running time is too large to be practical, and average-case complexity is difficult to determine without a model of the data. We have to be content with empirical timing results.

The searches that were allowed to run to completion spent most of their time building word graphs and counting tree-edges in the search for an acceptable word graph. Building a word graph and counting the tree-edges should take time roughly proportional to the number of words in the set. The number of word graphs built depends on the dimension of the final hypergraph (the number of position functions needed to get a graph with all edges distinct). The dimension increases with the size of the word set, but we have not determined the exact relationship.

The search program was written in C and run on a VAX 11/780 under UNIX $4.2 \mathrm{bsd}$. (The machine has a floating point accelerator, but floating point was not used in the program.) A $\log$ - $\log$ plot of the CPU time spent finding a perfect hash function versus the size of the set shows little scatter. Doing linear regression on the logarithms gives us the following empirical estimate of performance:

CPU seconds $=.059$ words 1.5 
Plot of CPU time vs. size of set

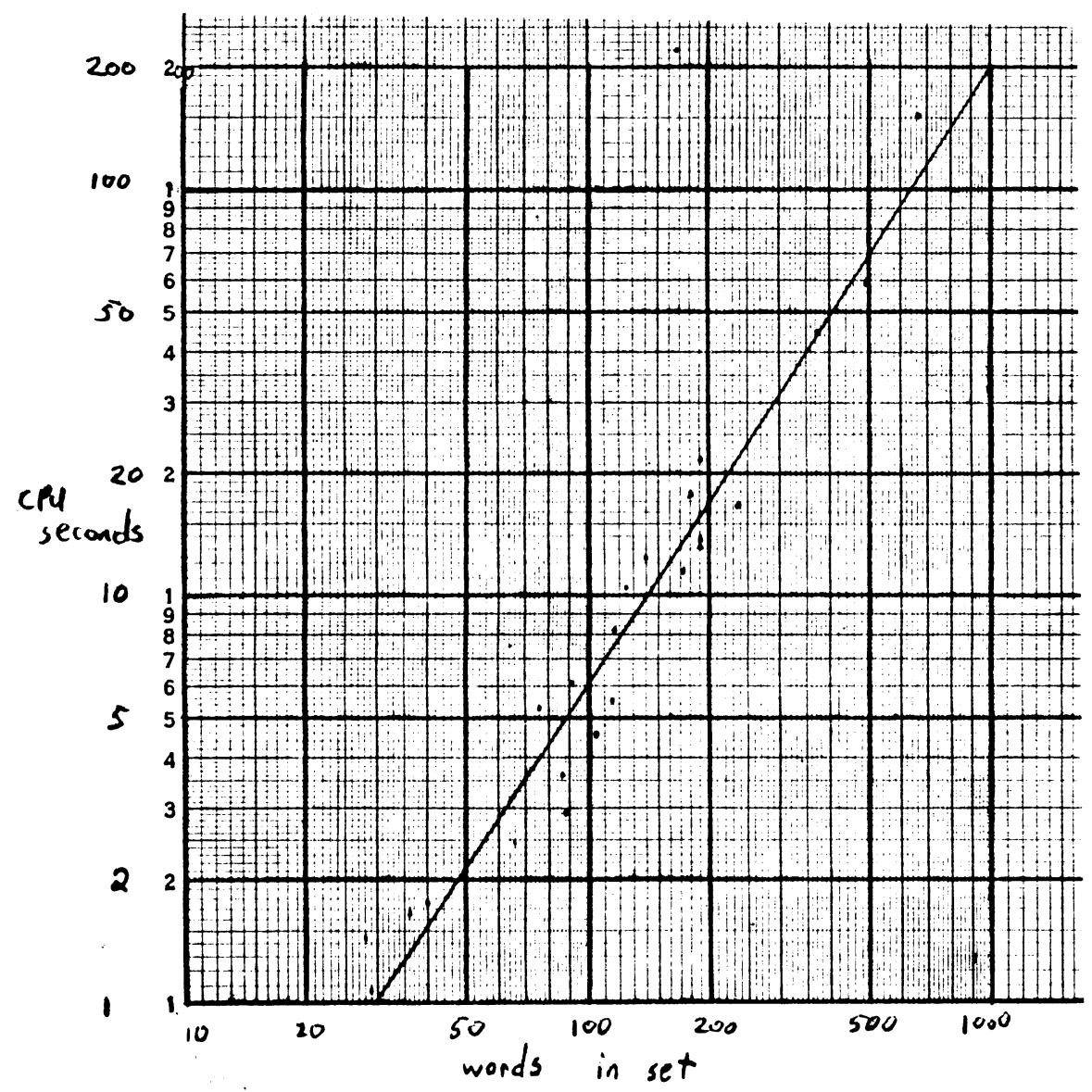

Future work

Non-minimal perfect hash functions for large word sets are fairly easily found. It would be interesting to analyze the dependence of the hypergraph dimension on the size of the word set, and the amount of extra room needed to find a perfect hash function quickly.

Since the searching algorithm currently used is potentially exponential, it would be satisfying to know that there is no fast algorithm for finding minimal perfect hash functions. We conjecture that finding minimal perfect hash functions for sets of $n$ words is NP-complete, but finding perfect hash functions with enough extra space can be done in polynomial time.

It might be worthwhile to investigate other classes of functions. As an example, word length could be just another dimension to the word hypergraph, and we could look for hash functions of the form $h($ word $)=8_{0}($ length $)+8_{1}$ (letter $)+\ldots+8_{k}$ (letter $)$. 


\section{References}

[C] Richard J. Cichelli. "Minimal Perfect Hash Functions Made Simple" Communications of the ACM 23(1) (January 1980),17--19.

[CW] J. Lawrence Carter and mark N. Wegman. "Universal Classes of Hash Punctions." Proceedings of the $9^{\text {th }}$ Annual ACM Symposium on the Theory of Computing, May 1977. 106--112.

[S] R. Sprognoli. "Perfect hashing function: A single probe retrieving method for static sets." Communications of the ACM 20(11) (November 1977), 841--850. 


\section{Appendix: word sets}

The sets of words used for hashing are listed here. The sets freg, pasc and pasc-id are from [C] (except that ODD and ORD are both in pasc-id). The set pasc-al/ is the union of pascand pasc-id. The set $c$ is the keywords and pre-declared identifiers of the c programming language. The set ibm is a subset of the IBM-360 instruction set. Those sets named rinumber were chosen randomly from a large spelling list. No distinction is made between upper- and lower-case letters. Apostrophes, hyphens, and other non-alphabetic characters are ignored.

\section{c.words}

auto break case char continue default do double else entry extern float for goto if int long register return short sizeof static struct switch typedef union unsigned while

\section{freq.words}

a and are as at be but by for from had have he her his $i$ in is it not of on or the this was which with you

\section{ibm.words}

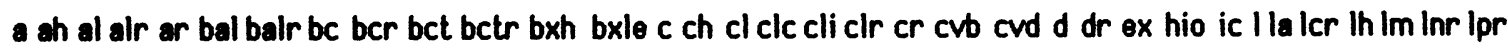
lpsw Ir ltr $m$ mh mr mve mvi mvn mvo mvz $n$ nc ni $\mathrm{nr}$ o oc oi or pack $s$ sh sio sl sla slda sldlsll sir spm sr sra srda srdl srl ssm st stc sth stm sve tch tio tm tr trt ts unpk $\times$ xc $\times 1$ xr

pasc-all.words

abs and arctan array begin boolean case char chr const cos dispose div do downto else end eof eoln exp false file for function get goto if in input integer labelin maxint mod new nil not odd of or ord otherwise output pack packed page pred procedure program put read readin real record repeat reset rewrite round set sin sqr sqrt succ text then to true trunc type unpack until var while with write writeln

pasc-id.words

abs arctan boolean char chr cos dispose eof eoln exp false get input integer in maxint new odd ord output pack page pred put read readin real reset rewrite round sin sar sart succ text true trunc unpack write writeln

pasc.words

and array begin case const div do downto else end file for function goto if in label mod nil not of or otherwise packed procedure program record repeat set then to type until var while with 


\section{r022.words}

Brahms chipping deluxe flux Germanic grandchild groom hallucinate ingratitude matinal Myers niece obtain pall perjury placeablePriam propyl Pullman snippy versa youth

\section{r066.words}

angstrom Aug beehive Bromfield Caldwell Carlson catchup changeover chi coach coiffure commensurable communal conquest cuddly cyanic Dominique downpour encomia enforce entitle equatorial franc frowzy gory gullet huh humpback inelastic inset keno knuckle lew livery London Mindanao pedal pinochle pogo pong presumptive quackery qualify quinine refuge revise rocky Salisbury sand satiable scissor secretariat sniffly snob Standish superb Switzer symmetry syrupy those transatlantic trisodium Valkyrie variac yawn zigzag

\section{r089.words}

albumin Algol antenna Appleby asterisk Atlantica Atropos band belove bemadden Berwick bough brow bud burgess camp capture caustic cookbook crayon critic derive desirous dreamlike duplex elastomer embolden embraceable esprit eve exalt fibrous forfeiture glued Harrington helmsmen hitting homage imprecise indignent inductor inshore intellect Kenney laxative leadsman lectionary Lilian macro maim monument Negroes nickname nondescript obese obvious organismic pearl pent pharmacist polyhedron procrustean purposive quip reagent scroll sound stew stride study Sumatra swain $t$ tallow tempest theocracy transparent Tyler typify urgent vain various Venice veto vocable wallow warty windbag windowpane

\section{r092.words}

adulthood adverse apices Arachne Argentina aurora autocratic basemen Bess bravery bum cartwheel catkin Chadwick Cincinnati coiffure concave conch consortium constitute contrariety Debra different downside drastic Duane Engle Ewing fed financial finial flack Forbes gable gawk granular inconsolable insular leatherback LIFO lilac Madame Madeline Magruder mamma matriarchal method militia Minnie miser missionary monel narcissist none nouveau Ostrander oxeye Pakistan pantheon paradigmatic Paso permalloy phantom pocketbook prairie prerequisite presidential prey purgative Ralston rampant regular sailfish Santiago Somerville star stew supervene swam Swedish symptom teletypewrite therapist transmittal update variant verbena wearied well win wisecrack witch

\section{r105.words}

alias alpha Annale Arlen as bacillus Beecham bicep bluegillboggle Bonaventure brave bridgework broach Bulgaria bursitis Byronic capstone chaste coexistent commerce confabulate contribution convene cord couch cream crossover cypress defendant diathesis discussant Disney diurnal ducat earphone embedder escheat Eva excisable extravaganza eyepiece Fabian foster frau frontiersman frostbitten gangplank Gertrude Glaswegian gog guile hack ham Humphrey humpty insufferable insurance inventive Jacksonian jut legato libidinous longstanding meridional metalwork Minneapolis molybdenum nicety notate Nubia obtrude oxidate pair pallid parson pauper perpetual piazza podge premonition quilt quirt receptacle remunerate reproach ring rubdown Sears seraphim sew soft solenoid sour sportswriter substrate successor sunrise Tananarive testate vow wavenumber wayside wedding Werner 
activate ambush Armata backpack berne beryllium bestubble bloom bosom bridegroom Brisbane bryozoa burp byway Byzantine cabal calla cape caught cleanse clinician congressman constrain cutback defrost desist dint distraught dragoon Edwina elfin equatorial exclusion fourfold glove grasp groundwork $h$ harvestman hull humidify idiomatic impracticable incise independent inhabit inhibitory interception invent Julie kilojoule Lin megalomaniac memory Messrs meticulous midget midshipmen Montclair mouthful Muong Nepal nephew Niamey nosebag nuptial object ontogeny optometrist organic pacemake paddle pass Paulette paymaster perish ping Piraeus plenty politico postage pouch precaution quadrangular rally renounce Ross rubbery scudding shah sibling snippet socioeconomic stableman stamen Suez sulphur Sumerian sunfish sunken switch Tallahassee tensional they threesome tycoon vanity vermin Viennese Vogel Waterbury whiten wishbone Zachary zesty

\section{r117.words}

6th abuse accent accidental acetone adaptation adaptive additive admitted adulterous Ampex anastomosis astigmatic barnstorm being Beloit Bloch Bolivia Boris BP breadboard callus certify chard Christianson climatology cog company coney conquer cormorant Cyprus dapper Detroit discordant discrete dishwasher disruption endorse ensign enslave ethylene familism farther finance flathead foyer fruition generic Glasgow grindstone guardian gunfire hardboard hardscrabble height Hitler hooves housebroken hydrolysis imbrue inactivate inlet insight instantiation leaden Lear Loeb logjam Malaysia Middlesex mimesis mischievous misshapen mnemonic Mohr moneymake motley ND neater neuritis not ordeal palmetto pander phantasy precipice presence proprioception quintet ray Rayleigh reside rubbing ruckus sanction saucepan Savonarola scientific scription sheath skeptic sketchbook soggy Spanish steak taxpayer Thebes Thorstein thou torque wadi waken weighty whereby yeah zigzagging

\section{r124.words}

AC Addison aster backplate bedtime Belshazzar Berenices Boeing Britain bum Camille Carbondale chronicle Clotho cofactor Coffman concierge concretion connector corny crazy dame daybreak deal delicatessen delusive depreciable diary drippy economic Ellisonemotional encyclical explicable farmland Faustus FCC FDA felt ferry gadget gale guinea Hadrian Hagen hailstone Haines Hamal house hurl hypotenuse imaginary impertinent inalienable Indonesian infect inflict insist intact intervention is Jansenist Kaskaskia ken lap lengthy lever lookup madman mainourished Marlowe McLean Monticello Negroid Nevins newsmen nipple notch obsolete outrageous Pabst Paul pavanne phenolic pity pocketbook pop pope predicament prefect presentation puberty pure python quiver rebelled roughshod seafare shipboard Sproul stimulate Stonehenge stopgap stylish summary suture sweater teeth through totalitarian turbinate urethane Velasquez vitamin Vladimirvolunteer vomit wah Walton whole widget Woodbury worrisome yarmulke

\section{r139.words}

adulate alphabetic anybody Appleton archangel Arkansas Atkins bebop benthic Blackburn blacksmith blutwurst bubble bustard cant cede chalcedony chipmunk commemorate corrigible cozen critique cure cutaneous datum declamatory decollimate densitometric dessicate diameter discernible disquisition dolly downspout drawback droop duke dusk earthmoving ecumenic embassy enlarge expeditious fake faulty Feldman finessing first Fitzgerald flung Gauguin get given glue grand grieve hamburger Hebraic Helmut hipping Howell ichneumon ignoble Illinois imperturbable installation IRS job jog ketchup kiss Lakehurst landau Lilian Loire malaise malformed mascara megahertz mensurable mode Mollie morgen naiad natural Nolsen Nero orate ordnance palate pampa Peter pharmacist pistachio pledge Pocono prim prompt prophesy punish quipping radium relinquish repairmen resonant reversion Rosalie Rwanda sack serum showcase showy sickle slogan Socrates Solon specie spheroid squashy squirehood stereography stock stylish Sudanese suffragette sulky superb supping surpass tensor Tientsin tomato TOPLAS touch transit Turing upon worship yellowish 


\section{r162.words}

abrasion agenda Aiken airmail Alexandra Allison allocable aloha amen American amply angry are Artie auction authoritative Baltimore barycentric benign bloodroot booklet bridgehead bull cacophonist camelopard catchup chandelier Christmas chub circumvent cocktail Coleman comedy compesition Contlin cowardice cramming criss cycle deadline default deluge depositor detergent diacritical Dido dockside drib Elysee etymology explicit extramarital Faraday fight finale formal Irancium Ginn glue glycerin Gould Gunderson hereafter hereof hypothesis immunization inapproachable inbreed incubi infelicity infinitum instead interception intracity jaze Jew jolt judicature Kaplan Karen Lancashire Laocoon Lisa Lucille Lyra magnetite Magruder Mendelasohn Mephistopheles midge MIT molal monarch neophyte nightgown novel obtain offer offset passion Paz philodendron physiotherapist pickaxe pizen pope poseur pray precipitous predominate probe prudential psychosomatic puddle qualify quarrymen ragging repelled repetitive retain Rhodes ripe sabotage saucy sawbelly serious set shortage slugging snowball spatlum sprain squishy strip sulfite Susanne swerve tabernacle tagging tao tend theoretician throbbing thyroidal timbre tonsil trafficking transoceanic urea valid vandal venial verbose virtuoso Waltham waveform whence Wirth woebegone yah yogi yon

\section{r181.words}

abstinent acclimate acquaintance airy Alec allergic Allis along also Amazon anatomy any apathetic apparatus armoire arthritis asthma Augustan axon bar behavioral beneficiary bookcase cant capillary centrist cesium Cessna characteristic cheat check checkpoint chink circumlocution Clarence clasp Cochran Cohen compliant composure corruptible cortex Coulter county courteay creosote dely degas deify dichondra digging dispensate dispersible domain dome Eleasar elicit Ellison enfranchise entire entirety equine essence esteem eternity extirpate fecund fickle floor footfall fraternity fraught funt Calatia Ceneva giggle grabbing graceful graduate Graff guru haunt heard hector honeycomb Illinois imitable impenetrable imponderable incarnate inequitable interferometric intravenous inversion jocular language larceny laurel Lexington Lois Lorraine malnourished McCowan memorabilia Merck meridional midget minuet Moen monument mosaic Nasareth Neff nodule oratory orb paperback pare Pegasus permalloy pharmacology phenolic phthalate powdery preface proviso Prussia rang rash rationale reduct rejoinder Rembrandt restive retrieve rifleman risky Romano round salmon Sandburg sausage schoolroom scud sharpshoot skied Slavic sobriquet somehow steadfast Stephenson stockade stratify strobe suction supine swabbing swift syrinx tab tackle that thing throwback toodle trajectory trip ultraconservative usurer Vandenbers vanguard verify vintage wavefront weight whack Whalen Wilbur Winchester Winnipeg Yugosiavia 


\section{r192.words}

academy adjoin Adkins aforementioned ahead alluvial amidst anagram arcsin ashy assiduous audience Augusta aversion avoid axis babbitt bail Bayport bezel bias biochemic bitwise bluebook bouquet breatfast broaden $\mathrm{c}$ cameo camp Canadian captor Carbone chinch codplece colony colossus conciliatory configuration confirmatory conservatory Corvus cotman Culbertson cumin Darlene decontrol define degree diatom diesel doorman Doris du dun duopoly emphases enigmatic entomolozy Ethan Eurasia evangel Faustian fluoridate foist fusty glow godmother goldfish gorse gradate hagerd hair hayward Hecuba hemming heroin hold hypocrisy impiety imposture independent indistinct indoctrinate instantiation intelligible intermittent intracity jockstrap Josephson judicious Justine Kentucky kola Kownlski lacewing laze lee lexical loegging Lowell Madeleine malice mammoth manslaughter Marlowe martyrdom melanin middleweight moccasin mode mortify nevertheless Newman Newtonian NIMH novelty nuclide oblong octahedron Olzon Oneida onset oodies optimist optometric oratoric pacify packet paraxial paraley patrol permitted perpendicular petticoat phenol Poland politician porterhouse post Prado prescript probe Pullman punish reach regale Regis relay rest roach saltwater San scaffold Schoenberg seclusion seditious serene serviette sheath shipboard slop soccer solicit spaghetti speateasy star stepchild sticktight stolen swishy symbol Tallahassee tangent tangy tantrum Thai Thelma trammel treatle triumphal two TWX unanimity USA vicelike Victorian Voss waggle weatherstripping wonder Yale

\section{r236.words}

Adelia Adkins advert again agglutinin ague Armstrong arsenic attainder attendee avow beard becket bedragele belt benefice Bernie Bertrand bethought bid binocular bivouac bran bravery breastplate caliper capacitor captious chalcedony chemisorb circulatory classificatory clerk coagulable cosatal coerce collocation confederate contextual contort coppery cotman cory cue curbside curia cyclist dactyl dart day decouple despotic dreadnought drench droop droplet ducat dully Edna encephalitis enervate enslave Eocene epistle epitaxy escapee Eurydice excelling extensor farewell Farrell faun feasible ferric figure linal float fluff foolhardy forthcome forthright forum foxhole foxy fraught furrow gaff Gil Gino glacier glide gopher great grubby handyman Hansel Harmon havoc heel Helmholtz hemorrhoid hereabout Herkimer Hieronymus Hillcrest ho Holm Holocene hornmouth hornwort hospital Hubbell huckster Huggins iconoclast impute incautious indefinable indeterminacy Indies inescapable inhale inspire insulin interlude irreconcilable jam Josiah kernel Khartoum kilobuck kneel knowhow kudzu length lethargy letterman listen locomotive lulu Luxembourg Mackey maid malformation manifestation Marsha marshal McKenzie merganser midst modicum mugsing nab neath nimble Northampton note nucleoli Numerische osmosis ovenbird pact path peed penultimate philosophic Phoenicia plagioclase Polaris prefatory prescript prolate pursuer quadrennial quandary quicken radiophysics rancorous rapacious religion revving Rio rouse Rowena satanic sedan Sepoy serene severalty Sherlock showman siderite signet Silverman snarl snippy snob Sparkman sporad ic squirmy stanch strontium suey sunbonnet sunburn Susan swag swant swum symposia synchrony tamaract tasel teaspoon tenon tentative text thermonuclear thesis threat trident troposphere tutu Ulysses uncle upset veracity Vivaldi Vulcan wanton warehouseman whirlpool wisecrack Wolff yen yeshiva 
abhorrent accelerometer adobe advisory Afghanistan aficionado agouti allegory alphabetic amble Americana amoebae Andean animism annual appoint Aristotle armillaria arose assimilate assumption attrition aural australite automata backplane Basel batwing beechwood Bengal Bertrand Beas Bhutan biceps biennial Bingham birdbath birthplace bivariate Bizet bleat Blinn bluefish bodybuilder borrow boyish Bradshaw brassiere broadloom business butchery caller cardiovascular Carey cassette chaff chalice challenge cherubim chortle chromosphere classy clink clubroom coagulable coax cockleshell coffeepot collegiate communion compassionate compendium compreas confluent connote consequential consist convalesce corny corralled corrugate crabapple cram crankshaft credulity cursory cut dashboard davit daze Decca decertify deputy desert detente Devon devour Dickinson directrix disembowel dispel divine Daieper dominion dote dramaturgy drug ducat echo Emily equinoctial estoppal exasperate exhibit expound exterior facilitate fence fete fever flange flannel flashy floodlight foe foolproof fore foulmouth furl furtive future gagging galley Galt gargantuan gaunt Cenevieve Gillespie glacis glamour gnaw godlike governance grabbing granola Grecian grill Gryn gypping h Hagen handmade heap hector heigh herb Heuser Howard Hoyt Hubbard humane Hurd ignorant improvise inactivate incontrovertible incumbent indium inefficient Ingram intimacy intolerant inventory irredeemable isochronous jarring judicable Judy Kevin kidnapping Kinney landau Langmuir laurel lexical libertine limpid load log lopseed lucre Lura lurt lush lysergic manageable Manley marshal masseur Mathewson Matthews member measage michigan microscopy millennium Missoula molybdenite monarchic monel monkeyflower Monticello moreen Morocco morrow mythic nadir naiad narrate Natchea nautical nepenthe newsmen NH Nobel Northrop nostril obdurate obtrude offshore opiate opt optoacoustic opulent outlandish ow paid palazei parquet partook peep peltry pendant penetrable pervasion petition phenomenal pillory pimple pinpoint pizzicato planet polemic portage posseman postdoctoral precinct predilect prefab prefix preview progression prohibit proposition proteolysis psychophysical purple quadratic quadruple quaff quill rankle recant recappable red referent Rembrandt Remington representative retail rhythmic ribonucleic Rigel rink rob rockaway rocky round saddle sandhill Sanford Sanhedrin sappy satiate Savonarola Savoyard schematic schoolwork screed scribble seizure service Sharpe shed shield shoelace shred SIAM Sicilian sincere sinful sinistral sisal Sistine Smithsonian solicitude somatic sorghum soundproof Spanish sparge spectrometer spectrometric spent spiderwort Spiegel staid Stanton steady Sterno stockroom street stumpage stumpy stunning subpoena suggestible sunset surface suspend suspense swimming talon Toledyne template tenspot terse Theodore therapist Theseus tor tory treatise tremble trial trite trunk TTY tub tundra tweed twirl unanimous USGS vagabond vicelike Victorian Wehr wheelchair wildlife Williams Winslow Zomba

\section{r495.words}

aboard absolve abstractor abut accordion acme actinium ado Aeneas afferent affirmative afresh agnostic Aleck alma altern alveolar Americanism anthology apiece apostate aqueduct arena Arlington arsenide arty aspen astrophysical atlas Atreus attendant audio avocet backboard ballad ballast ballet banter bare barnacle barometer Bator beauty been belittle Bengal Berenices Berkowite Betelgeuse Bhutan billet bisque bloat blond BMW bock Bonn boorish bottle bowl bracket Brunswick Buddha bug bulk bullseye burbank Buttrick Buxtehude c cabana cahoot calfskin cannonball Capricorn cardinal carpenter casual caustic cautionary celestial Cessna chair 
Chambers charring cheese chemisorb Chinook chloroform chromatograph cider clan Clart claustrophobic client cliff coalescent code cognition comb comeback concentric concrete confession conn convivial cook copolymer corpulent cortege cotta cougar Coulter counteract courtesy cowl cowlick craft Cummings Cummins cupric cutting dachshund Datota Daly Darlene date De deathward decathlon decelerate deck deity deliberate derriere dick diet diminish dinnerware ditty Dixie dock doff Doge Doherty dormitory dun eager ecliptic edify edit electroencephalograph Ellen embody entourage enunciate erupt ether etiquette euphoria Eva eventful exemplary exercise exodus expelling exposition fabulous famish fanfare farewell Farnaworth Faustus felony Fibonacci fish Fitch flatworm follicle fosterite Franz Frazier freehold Irontier Irustum gadolinium gallus Gambia garter gentry Gibbs glare Glenn glitch glitter Goren grabbing granary gravitate growl guild gunfire Gunther gyrfalcon hackmatack handicapper hegemony heighten Hendricks Hermosa hex hipping Holstein homeland hop Horace hornblende horticulture hose hostile hunch hunt hydroelectric hying IBM icing iconoclasm iffy immerse impend impish impolite inconsequential indelible indigent inflate inheritor inning insatiable inscription insist intemperate intracity irreverent lsaac Jackson Jacqueline jamboree jitterbug jotting jubilant Julius Juneau key kittenish knives knobby Knoxville kolthoz Kramer Krieger Kruse Kurt Lave Lawrence Lear Leeds leonine libel librarian longevity loot lovebird loy lyricism macintosh magic manpower marketeer marriageable martin maser mason maw maxima McCarthy McMullen Mercator meritorious meteor Methodist Methuselah micro mid milestone minimal misosyny Mohawk monies Mormon mortem mortise Moyer muskmelon muslim mutate Mycenaeen mycology myeloid Mynheer Nashville needn't nest neuroanatomy newcomer nib niggle nomenclature nucleic nuptial objectivity obscure obsidian obtain Odyssey officio opinion optimum ornery osteoporosis otter oust Palomar parametric parrotlike pater peal pectoralis pedagogue pelvis Pensacola perch perfusion permissive pessimal pessimism phalanger pickup plaintiff planeload plantation plodding plump polio polopony pompano postmen predominate presentation pretense procure prophesy puzale qua raffish railroad ray recursive remunerate replaceable resilient retinue revision rhododendron Riggs rockaway rocky rout rubdown Runnymede russet Ruth Rydberg Sadie salacious salivary salutation salvage sandstone scapular schoolroom sclerotic seafood seal seedy selenite shanty Sharon shoddy shutout Shylock sift sinusoidal sisal sistin steleton Stippy stylark slid snivel soccer sodden solicitor sorcery Sorensen spacesuit spatterdock spite Spotane spur squall stairway Standish star statesmen stepwise stick strophe Styrofoam summon SUNY surrogate swiss sword symptom synopsis syntheais talk Tammany Tanaka tantamount taunt teleprinter temple tentacle terrier teatimonial tetragonal thatch Thea Thebes thermodynamic thorough thrash thrill throw toady torpid total tras transposition trespass triangulate truly twitchy typoerapher umbilical valentine vassal veal veterinarian vexatious viscount Voss votive voyage wakerobin want war warfare washboard waste weatherbeaten webbing whimper Whitcomb wintertime woodpeck woven yaw yea yodel yore you'd Yukon 


\section{r667.words}

abalone abdominal aberrate abysmal Achilles acid adherent adjourn administer admix adventitious adversary aerogene agleam ago ahem alb allergy amalgam amorphous ampersand analogy Annale annum anorthic apostate apparel appellant approbation ardent argillaceous aristocratic arraign Ashmolean assent assert astride Atwood autonomic autumnal Azerbaijan aximuth azure badge Batu baleen Bambi barber Barclay barony bed begging beginning bellmen belt benzene beret betel beware bezel Bhutan biometry bishop bitch bittersweet blade blockage blockhouse boa boatmen boon bootstrap Bosch bothersome boycott brazen Brest Brian briny Bristol brothel bryophyta bulb bureaucracy buried bursty butch butene cachalot Cady calumniate Calvary Cambridge canal canvass capella carcinogen career carouse Carruthers centerpiece centroid cerium cerulean chafe chance chantry chaos cheap Chen choose choppy choreography chrysanthemum churchgoer churchyard circlet citrate Clarence Claudia clearheaded cliche Clifford closet cloth cloture cobble coccidiosis Colgate colicky collapse combatted comedy compile component compote comprehensible compression concur condemn Conestoga conferring conformal congest conscription consent conservatism consist convey Convay cookbook copolymer cornea Cornelius Coronado coroutine Corvus cosmopolitan covenant cover crackle crafty Cramer crania crematory crew cricket cried croak crupper cubic cultivable CUNY curlicue Cushing cushion cutworm Cynthia Dadaist dais dateline Davies decelerate deconvolution deficit demise demon Denmark depressed desecrate desiderata desideratum detector deterrent deus dismal d'oeuvre dogberry Dolan dolphin Domesday dossier dynast earwig eat ebony editor cerie el electrocardiogram Elisha ellipsoid energy enquiry enrich enroll enthrone epaulet Ephesian establish estate Etruscan eventful excommunicate exculpatory exemplar exhaustion exhilarate expenditure extension extensor extricable eyeball FAA face fag fairy fanciful fare fast feather ferocity ferroelectric fetter fettle fibrin fickle filler fireplace fireproof fiscal fisticuff flak flake flam flapping flaxen Fleming fondle fox Frenchmen frilly frozen fugitive fuse gel genealogy gentlemen geopolitic gestalt Gilmore glad glassware glean glycerol godparent Codvin grandfather graphic grease greatcoat gripe Guam gunning Gutenberg hangar Hanoi hardtop hardworking hatch heady Hercules hermetic hesitate Hewitt hexameter Hibbard horseman Huber Hugo hundred hydrochloric hydrochloride hypothesis ibex identical ignoramus imbroglio impiety implicant inasmuch incalculable incestuous incidental indigestible indiscreet indwell inequity inevitable inexorable inherit inquest insight insufficient intemperance interior interrogatory invariable involutorial ionosphere irradiate Irwin Joan jolly Jr j's Judith junta kaolin Katherine Kauffman keop Kelsey Kelvin Kendall key Kimberly knives knowledgeable Knowiton kumquat land Lange Larsen layoff left Len Leon Leroy Lesotho libertarian libretto lignum limbo liquor lobo locust loincloth Loire lord Louvre lucrative luke luminosity madrigal mailman Malagasy manometric manslaughter manumission Marie Marrietta martini mastermind materiel maximum maxwell menace Merle Mervin mesa metallurgy mien Millikan milord minuet modulate momentum Monroe mosaic mossy motel mountain multiplicity Mumford myofibril naive Nanette Nanking Nash Navajo nay nearest neon nervous nettlesome neuralgia neuropsychiatric Niagara nibs nickel nigh nirvana NM northwestern novitiate numerable occult o'clock officeholder OK optoacoustic ordeal $O$ 'Shea oxen p paintbrush palliate pang pantheist parenthesis Parisian passport path patrol patty pecan pedeatrian peepy Pegasus pelvis pepperoni Perle permission persist perspicacious pertain philosoph phraseology pilewort ping pion placental pleural polygynous porridge portend Powell praseodymium preliminary prince prizewinning productivity profound prolongate propagate prospector protege prothonotary prune psychosis puckish Pulitzer purgatory puritanic pursuit 
quaint queen quick quit rabbet racy radiography radius radix raj Ramsey ransom ravel realtor rectangular reduce repentant reside restraint retrogress revisal revival Ripley Rosenberg roughcast roundhouse saga sagacious Saigon salesperson salvo samovar Sargent scheme Schuylkill sclerosis scopic scoria script scrutiny scull scurvy sedan Sepoy Seton seventieth Severn shipyard shish shod showroom sidewise sienna signpost silane sill sinh sinister sire Sistine skill skyrocket slavish sleepy sludge smaller Smithson snapdragon Sofia solvent soma southernmost span spate Spaulding specie splash splintery spurious stain staminate staple stasis stature stave stem Stephenson sternum Stevens stringent striven strum stuff stupor Sturbridge subject subliminal succubus Suffolk sulfa suntanned suppose surgery swathe sweater sweep swelter swerve tachometer tact taffy tanager Taos tardy teasel teaspoonful tecum teen Telefunten teleprompter ten Terre textual Thayer the thyrotoxic tipping titular tolerant Toni tonsillitis transgress transmitted transpacific treasury trellis tribunal trichloroethane trinket triumph trivium tunnel twisty typesetting ubiquitous Ullman van variac verify vermilion vesicular vexatious victorious viewpoint villa volatile waken wallet washbasin washbowl Watson wax Webster whale whereon whet wig wildfire willful wingtip Winnipeg winnow wrongdoer wrongful yawl yearbook Yeats yet zeroth zeta Zoroaster

\section{r992.words}

aborning abrasion abscisase accipiter accord accrue acme acquiescent addend Addison additive adject ado advantageous advisee aerogene aeronautic affluence agnomen aile Albania Alex Alexis aliphatic allyl aloha although alway ambiguity Americana ammo amort Angeline anionic anorexia ante Antioch anyway apostolic appall arbitrage Arden Argentina aspheric assail assiduity assign astonish atonal attitude audio audiotape austere auto automate automatic avenge award awful awtward ax aye Aylesbury babyhood Bach bactside bacterium ballot Bambi baneberry barbudo bark Barnard barricade baseplate basophilic bathrobe bayonet bazar beacon beauteous Becker bedtime beget beggary begotten belate below bemuse beneath benefactor benthic Benz Bergland Berlin bestseller bicarbonate bicker Birmingham bite bled blest blonde Blum blurry Boca bong bopping born botanic bothersome boulevard boutique Boylston breadfruit breatfast breastplate breech bricklayer Bridgewater brittle broken Bromley bronay brouhaha Bryan bulk bunkmate Burnside burnt bursty Byzantine cabbage caddis Calhoun calico Callahan calm Cambodia Cameroun candy capella captious Caputo caravan Carbone cardiology careful Carlo carload carney Casanova catatonic catfish Cayuga ceil centennial Cetus Chad chairperson chamber chance chap checkout chemistry cherub chicanery Chinatown chuckle chuff Churchill cinematic Citroen cityscape clamp claustrophobia clean clergymen clint clockwork clothesbrush Clyde coed Cohn cohort colossus commend commentary commissariat committing commodore compel compress compression compressive concerti configuration Conrail consent consistent contradistinct contrast cookbook Cornelia corralled corrupt corruptible counteract coverlet crap crash crase creak creating creek crucify culinary culprit culture cumbersome cunning curio cycad Cygnus dachshund darn deafen Deanna debarring debugging debutante decedent deerskin defensive defocus deft demagogue demean demon demonstrable denial dentistry descent descriptor designate Desmond deviate devil Diogo diffract dilation diopter diorama disastrous disciplinary discipline discretionary disembowel disparage ditch Dixon dodge doe doleful Doris Downing dream driven drool drosophila drudgery dulcet duplex dustbin ear eardrum Econometrica effete egregious Eileen ejector Extachrome electoral Ellis elm embattle embouchure emolument employer encryption enter entertain envenom envision epithet Epsom erase Erasmus erotica errancy escapade eapionage Evans Evanston evergreen evocate excommunicate executive exhort exogamous exposit extolling 
extort Fabian Fairfax faithful falcon Farber farce Farley Farmington fasciculate faucet feminine fiasco finish firebug firework fizale flammable Flanagan flint flinty flock flood Floyd focus folio Fomalhaut foolhardy forbore Foss Irantfurter Iraternity freedom fresco frivolous front frontal Irontiersman frothy Irozen fuel Iunnel gable Gail Galbreath gallinule gallows gander Gannett gaur gear gent Gettysburg gibby Gifford Gilligan gird given gladdy Glidden glimmer glitch glossed glottal glove goggle Coliath Coodman gorilla Corton gradient grain grammatic graven grilled gristmill Guam guard guess guilty Gullah gunpowder Gurkha Haag habitual halfhearted handicapping handset happenstance harbinger hardtop Harlan Havana hazard heady hearken hearth heathenish Heine helpmate Henri hexafluoride hey hippy hire historic hitch hitting holt Honduras honeymoon horoscope Horowitz horseback hostage how humble Humboldt humerus hundredfold hurray hyaline hypothetic IBM Icelandic icy idol idyllic ignorant impute inapt inaugurate inborn incalculable inceptor income incompressible inconsolable incorrect increase incredulity incredulous incriminate incubus inductee industrial inept inertance infantryman infarct infect infelicitous infer ingather inglorious ingot inhabitant innovate inset insidious insolvable inspiration intellect interject interrupt interruptible intestate introductory invariable involute irtsome irrefutable isochronal isocline isotherm item janissary jelly jockstrap Johanson journalese Julio justify kaleidoscope Kamchatka Kathleen Katmandu Kelsey keynote kilobuck Kipling kite knowhow knowledge knowledgeable kulak Kurd Kyle lace lance Laocoon larceny Larsen lean leap legislature leitmotif leitmotiv lest Leviticus libel libido licensable lifelike Lindsay lithology lithospheric liveth locust lodgepole Loomis loot Lotte Louis lousy lowdown luminance lurid lustful lutetium macro madcap madstone magazine Malabar malaprop malfunction malpractice mandarin mane mantlepiece Margery masculine masonry masquerade masterpiece Mathews mature McCann McCullough McDougall McGuire Merriam merrymake mesa meteor mettle Middleton midweek might mike militate milk minaret miniature minor Mira misery moccasin mockery modicum Moiseyev moisture moment monastic monies Montrachet morn Morristown motivate mountainside mousy mugho multiplication mustang mustn't mutant muzzle mystify NAACP naiad natty nausea nave NCR nearby nebulous necropsy neurasthenic Newbold Newell newscast newsreel nightdress ninefold nitpick nodding Noel noisemake Noll nominee nonogenarian nook Northumberland noticeable nova novitiate nu nuisance nutrient obese obliterate occident octogenarian octopus octoroon Oedipus old onerous ordnance Orestes oriole orthicon orthography oscilloscope ozone pack pal pamphlet panning parochial Parsifal participle particular passe patchy paycheck PBS peaky peat pedantry pee pellet pennyroyal pep perpendicular persecutory perspicuous Perth pet Petersburg Peterson phenomenon philodendron phonetic pianiat Pickford Pierson pigtail pinscher piracy pitchstone placeable plagued planetaria plaque Pleiades plethora pliant plod poach pokerface polar Polaris pollution ponderous pony portulaca possession practical preach preclude presumption previous proclamation proffer promote pronunciation prophesy propyl protagoniat Proust proverbial psychoanalytic psyllium pupil puppyish purl purposive purr pursue pushbutton pyroxene Pythagorean quadrant qualified query question queue quirty quixotic radices raffish rat ravel receive reciprocate recluse redemptive refinery refractory refutation regime remnant renewal repellent replica reprisal requisite rescind resilient respiration retrieval reverberate revere rheumatism rid Ridgway rig rigid riotous rivulet Roberts rollback Rome rondo root roughen round roundtable rudimentary Runge Russia rye sail sandpile sandpiper satin satiric satisfactory Saturnalia saute scabbard scandal scare scarlet scary scenario scenery scheme schoolbook schooner scope scoreboard scrim scum scurrilous seam seashore seater seeable sera Seton Severn Seville shedding shimming shiplap shipwreck shopping shortstop show showy shrapnel SIAM sidewise silk siltstone Sims sinewy sinus skew skittle 
skullduggery sky slash slat slaughterhouse Slavic slender slid slob slough Smithsonian snail snowiall snuggle soesgy solstice sometime sort Spartan speckle spectacular spicebush spigot spontaneous spoof sprout squashy squatting stardom stateroom statuette steamy stella stellar Stewart stirring Stockholm Stockton stool stop storeroom strawberry strawflower strict strontium stumpage substantial succinct suck suds sulfate sulfuric sulky summitry sunlit supernatant supplementary suppress surrender swat swimming sycophant Sylvester tambourine Tananarive tara taxation teal technetium technique technology Tektronix tenacity territory terse Teas testimony that'll thee their thermionic thin Thor thorn threefold thuggee thyroglobulin tick timeworn tinsel tip Todd togs tomatoes tombstone Toni took toolsmith toothbrush topaz topnotch total traceable tragedy tranquil transceiver transmissible trepidation trigonometry trilobite tripartite triumph trotting truancy true trundle tsarina Tulsa TVA twice upon upshot urgent USA usher utilitarian vendetta venerate vernier via viburnum victim videotape villa Vishnu vista volley Volstead Vreeland wallow Wang wardroom warehouseman Washington wasn't Wasserman watercourse Waterhouse wayside wherewith whimper whirl whoa wife windfall winemaster winnow wise withdrew wop worse writeup x's yarmulke yawl yeasty Yugoslavia 